\title{
Pollen Germination and Pollen Tube Elongation of Tomato (Lycopersicum esculentum L.) Regulated by Cell Wall Invertase through Sucrose Hydrolysis
}

\author{
Astija \\ Universitas Tadulako, Kemenristekdikti 94119, Indonesia
}

\begin{abstract}
Sucrose is a sugar required for pollen germination and pollen tube elongation. It is little known on the regulation mechanism. As such, this research was conducted to reveal mechanism pathway of the sugar in regulating pollen germination and pollen tube elongation by cell wall invertase. The pollen grains, respectively originated from wild type and transgenic tomato plants, which had been silenced their inhibitor gene (INVINH1) of the cell wall invertase were used in this study. The pollen grains were cultured in media containing glucose, fructose or sucrose. Results of the study showed that percentage of the pollen germination derived from transgenic plants was much higher than that from wild type plants. Moreover, pollen tube elongation was longer in transgenic plants compared with wild type plants. Interestingly, these results were observed in medium containing sucrose only, but not in glucose and fructose. This result suggests that cell wall invertase activity regulates pollen germination and pollen tube elongation through sucrose hydrolysis.
\end{abstract}

Key words: Sucrose, cell wall invertase, pollen germination, pollen tube elongation, tomato.

\section{Introduction}

In flowering plants, reproduction process occurs by involving the union of the male cell (pollen) and the female cell $[1,2]$. The process is preceded by the occurrence of pollination, a process during which pollen grains come from the sporangium of anther land on the surface of the stigma. The pollen grains are facilitated by pollinator agents, such as the wind, water, animals and humans. Each plant species has one or more special agents. The pollen grains interact with stigma, and undergo germination and elongation. Both processes involve physiological, biochemical and genetic aspects [3-5].

The pollen germination process begins with an event of rehydration or water absorption from papilla surface of stigma through a certain structured site of the pollen grains called "aperture". At this place, the cell wall structure of the pollen grains is thinner with

Corresponding author: Astija, associate professor, research field: plant science. little exine (outer layer) than in other parts [6]. The rehydration occurs as a result of the hydration experienced by pollen grains after those exit from the sporangium and is present in a hot or dry outdoor environment [7]. The absorption leads to an increase in turgor pressure that can ultimately loosen a plasma membrane and cell wall of the pollen grains [8]. In addition, the absorption stimulates enzymatic activity and metabolism of the pollen grains. The stimulation results in pollen germination [9]. The germination that occurs through the aperture will continue to form the bulge of the plasma membrane and its cytoplasm outward to produce a pollen tube [10]. The pollen tube extends and penetrates the cells of the pistil tissues. This elongation is intended to deliver the generative nuclei to meet the egg nuclei and polar nuclei for the fertilization process that produces the embryo and endosperm, respectively. This process takes place inside the ovule [11].

Several studies have reported that the elongation or growth of pollen tubes to the ovule is regulated and 

Regulated by Cell Wall Invertase through Sucrose Hydrolysis

directed by chemicals or chemotropic substances derived from pistil tissues [12]. These substances, such as sugar, fat and protein, are important regulators in germination and elongation. Sucrose is the final product of photosynthesis which has a crucial role in regulating plant growth and metabolism [13-15]. Sucrose is transported by the vessel element and its companion cell to enter the sink cells in two ways, i.e., the apoplasmic and simplasmic ways. The apoplasmic way is the transportation of substances passing through the cell wall, while the simplasmic way is passing through the plasmodesmata [9]. By the first way, sucrose into the cell wall is transported by a sucrose transporter and hydrolyzed by the cell wall invertase into glucose and fructose, which are then transported into the cytoplasm by a monosaccharide transporter (hexose transporter). Cell wall invertase activity can be inhibited by a protein inhibitor that causes hydrolysis of sucrose into glucose and fructose decreases [16]. The inhibitor protein is located together with the cell wall invertase enzyme in the cell and the inhibitor works posttranslation [17]. On the other hand, the second way (symplasmic transportation) occurs when sucrose enters the cytoplasm through plasmodesmata, a cytoplasmic relationship among cells $[18,19]$.

Pollen loses its simplasmic transportation. It is likely that the transport of sucrose from the outside into the cell occurs via apoplasmic. This hypothesis is based on a proposed transport model that sucrose enters from extracellular pistil tissues into the cytoplasm through the pollen cell wall [20]. It is further proposed that the sucrose within the cell wall will be hydrolyzed by the invertase enzyme (cell wall invertase) into glucose and fructose. If the hypothesis is proven, the role of the invertase enzyme becomes important in the pollen germination and the pollen tube elongation through the regulation of the breakdown of sucrose and the regulation of the supply of substances in the cells to regulate osmotic pressure, growth, metabolism and sugar signals within the cell.
Recently, the role of invertase enzymes in regulatory processes has been extensively studied in different plant species by altering their genes or inhibitor genes. For example, silencing of LIN5 gene included into cell wall invertase leads to a reduction in fruit size, increases the rate of abortion of flowers and shows the different structures of fruits and flowers [21]. Conversely, the inhibition of the cell wall invertase inhibitor, INVINH1, leads to an increase in cell wall invertase activity, hence a twofold increase in fruit production, delayed leaf aging, increased hexose levels in fruit and seed [16]. In addition, studies conducted on the development of pollen showed that cell wall invertase silencing resulted in abnormal forms of pollen and sterility pollen in tobacco plants [22], and a decrease in pollen germination from tomato plants [21].

This paper aimed to reveal the mechanism of cell wall invertase in regulating pollen germination and pollen tube elongation via sucrose hydrolysis.

\section{Materials and Methods}

\subsection{Genotype Analysis of Transgenic and Wild-Type Plant DNA}

The pollens, respectively originated from transgenic and wild-type plants, were used in this study. To verify the genotypes of the two types of plants, genotypic checking was performed using PCR method. Cotyledon of four plants of each type was used to extract genomic DNA to verify the genotypes. Cotyledons with size of $1 \mathrm{~cm}$ wide and $2 \mathrm{~cm}$ long were excised and placed into a $1.5 \mathrm{~mL}$ tube, followed by immediate immersion into liquid nitrogen before storage. Genomic DNA was isolated from the frozen samples by crushing with a tooth pick, and $1 \mathrm{~mL}$ of the extraction solution was added before tubes were centrifuged at $10,000 \times \mathrm{g}$ for $10 \mathrm{~min}$. Extraction solution consisted of $0.35 \mathrm{M}$ glucose, $0.1 \mathrm{M}$ Tris- $\mathrm{HCl}$, $50 \mathrm{mM} \mathrm{Na}{ }_{2}$ EDTA, $2 \%$ PVP, $1 \% \beta$-Me and $\mathrm{ddH}_{2} \mathrm{O}$. The supernatant was discarded and the pellet was added to a $600 \mu \mathrm{L}$ lysis solution. The lysis solution 
consisted of: $1.4 \mathrm{M} \mathrm{NaCl}, 0.1 \mathrm{M}$ Tris- $\mathrm{HCl}, 20 \mathrm{mM}$ $\mathrm{Na}_{2}$ EDTA, 2\% CTAB, 2\% PVP, $1 \% \beta-M e$ and $\mathrm{ddH}_{2} \mathrm{O}$. The lysis process was conducted using incubating at $65{ }^{\circ} \mathrm{C}$ for $30 \mathrm{~min}$ turning over every $10 \mathrm{~min}$. To separate DNA from the dissolved protein or other materials, the solution was then added to a $600 \mu \mathrm{L}$ solution mixture consisting of chloroform and isoamyl alcohol with a proportion of 24:1. The solution was again centrifuged and dissolved with chloroform in isoamyl alcohol (24:1). The solution was shaken 30 times and centrifuged at $11,000 \times \mathrm{g}$ for $10 \mathrm{~min}$. The DNA-containing resultant solution was transferred $(500 \mu \mathrm{L})$ into a new tube to which $500 \mu \mathrm{L}$ of chloroform in isoamyl alcohol (24:1) was added. After mixing and centrifuging at $11,000 \times \mathrm{g}$ for $10 \mathrm{~min}$, the DNA, upper layer, was then transferred $(400 \mu \mathrm{L})$ into a new tube. To precipitate the DNA, the solution was then added to $40 \mu \mathrm{L}$ sodium acetate and $240 \mu \mathrm{L}$ isopropanol. The solution was kept at $-20{ }^{\circ} \mathrm{C}$ for 15 min or continued immediately to be centrifuged at $11,000 \times \mathrm{g}$ for $10 \mathrm{~min}$. The supernatant solution obtained was then discarded and added $1 \mathrm{~mL}$ ethanol (70\%). Thereafter, the solution was mixed and centrifuged at $12,000 \times \mathrm{g}$ for $3 \mathrm{~min}$. The precipitated DNA was washed by using ethanol $(70 \%)$ repeated three times and dried for $5 \mathrm{~min}$. The purified DNA was then added $50 \mu \mathrm{L}$ ddH $_{2} \mathrm{O}$ for smaller DNA or 100 $\mu \mathrm{L} \mathrm{ddH}_{2} \mathrm{O}$ for bigger DNA. The DNA was kept at $-20^{\circ} \mathrm{C}$ or used immediately to check its quality

PCR was conducted using INH primers designed using PRIMER-BLAST from NCBI. The primary pair obtained from the program was forward primer: TGTTGGTAGAGCCATTGTAAGA and primary reward: GGGGATACACACATAACATTTGAGG, with each TM 57.1 for forward primer and 59.7 for primary reward, and the size of the expected product was $200 \mathrm{bp}$. The primer will detect the INVINHI of genomic DNA of wild type and control plants, which encodes a protein inhibitor of the cell wall invertase enzyme. The control plant was used for positive control in that the plants that had been known the gene.
In addition, negative control were used using the primer added without genomic DNA (or water) in the mixture.

The transgenic plants were a silenced-inhibitor gene (INVINH1) of cell wall invertase enzyme through RNA interference (RNAi) technique [16].

\subsection{In Vitro Germination and Elongation Assay}

By the genotypes analysis, each of the four plants used as samples in this study has been ascertained origin from transgenic or wild-type plants. Furthermore, these plants were then kept growing in the greenhouse. Plants began to enter the reproductive phase, when they have reached two and a half months with the appearance of the inflorescence. Once entering the anthesis stages, pollen grains from a sporangium were removed by vibrating the flower stalk with a vibration device (Vibrator).

The pollen grains of each flower were collected into a tube sized $1.5 \mathrm{~mL}$ and of which was added $1 \mathrm{~mL}$ of distilled water. After stirring for $15 \mathrm{~s}, 20 \mu \mathrm{L}$ aliquotes of these pollen suspensions were cultured in $1 \mathrm{~mL}$ media with a mixture of $20 \mathrm{mM}$ MES, $60 \mathrm{mM}$ PEG 4000, $2.964 \mathrm{mM} \quad \mathrm{Ca}\left(\mathrm{NO}_{3}\right)_{2} \cdot 4 \mathrm{H}_{2} \mathrm{O}, \quad 0.811 \mathrm{mM}$ $\mathrm{MgSO}_{4} \cdot 7 \mathrm{H}_{2} \mathrm{O}, 0.989 \mathrm{mM} \mathrm{KNO}, 1.617 \mathrm{mM} \mathrm{H} \mathrm{H}_{3} \mathrm{BO}_{3}$ with the addition of one of $58.42 \mathrm{mM}$ sucrose, glucose or fructose.

The germinating pollen was indicated by a cytoplasmic outcrop that comes out of the aperture of the pollen wall by reaching less than or equal to the diameter of the pollen. The diameter of the pollen from tomato plants has an average size of $20 \mu \mathrm{m}$ [23] . Pollen germination and pollen tube elongation of four individual plants of each treatment were observed for $3 \mathrm{~h}$ at $25^{\circ} \mathrm{C}$. Using a microscope, the percentage of the pollen germination was calculated by comparing pollen germinated with the total of the polen grains (pollen germinated + pollen un-germinated), while the length of the pollen tube was calculated by using the Image J program.

Then, changing the different sugar concentrations 
with $29 \mathrm{mM}$ sucrose, $58 \mathrm{mM}$ glucose and $58 \mathrm{mM}$ fructose was conducted to examine whether the effect of cell wall inverase activity on pollen germination and pollen tube elongation was dependent on sucrose only. The used methods were similar to pollen germination and pollen tube elongation methods as described above.

The significant differences of the pollen germination percentages and length of the pollen tubes were analyzed by ANOVA one way using JMP version 11 program.

\section{Results and Discussion}

\subsection{Genotype Analysis}

From the PCR assay, it was found that four wild type plants had the expected genotype of the wild type by showing the DNA bands of the INVINH1 gene. While the four plants of the transgenic plants did not get the DNA band for the INVINH1 gene (Fig. 1).

\subsection{Sucrose Promotes Pollen Germination and Pollen Tube Elongation}

The growth of the pollen tubes in a liquid medium added fructose, glucose and sucrose was shown in Fig. 2. Pollen grains cultured in media containing fructose (Fig. 2a) showed that there was still a lot of un-germinated pollen, compared to those in media containing glucose and sucrose. Additionally, the pollen tube in the fructose media (Fig. 2a) elongated shorter than those in the glucose (Fig. 2b) and sucrose media (Fig. 2c). Even the pollen tubes in media containing sucrose were the longest. These results indicated that sucrose promotes pollen germination and pollen tube elongation.

To determine the percentage of the pollen germination, number of pollen germinated to total of the pollen was calculated. Results showed a significant difference between the pollen germination of transgenic and wild type plants from medium containing sucrose. Percentage of the pollen germination coming from transgenic plants was higher than that from wild plants. Compared to medium containing glucose and fructose, the pollen germination in the sucrose medium was the highest (Fig. 3).

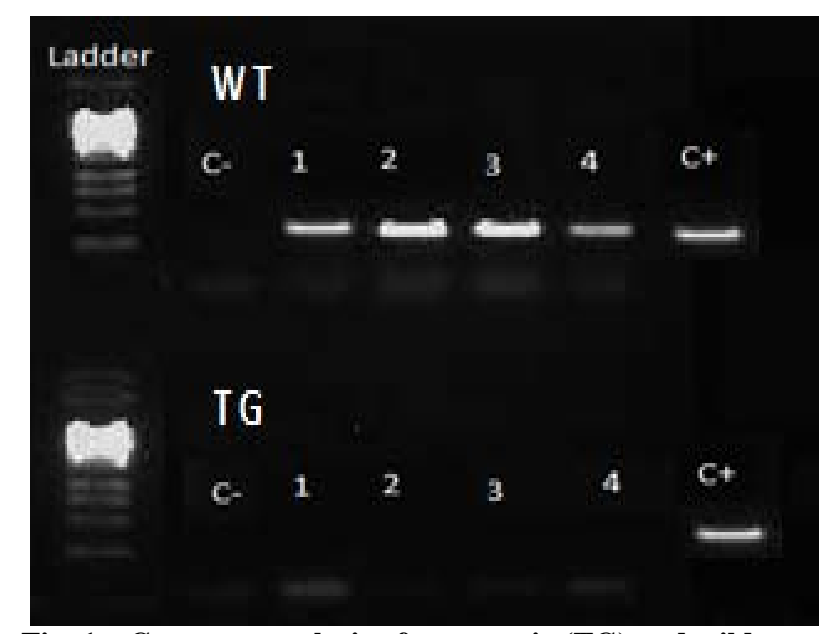

Fig. 1 Genotype analysis of transgenic (TG) and wild-type plant (WT) DNA.

INVINH1 gene was detected in all four wild type plants and the positive control plants $(\mathrm{C}+)$ but not detected in all four transgenic plants and the negative control (C-).

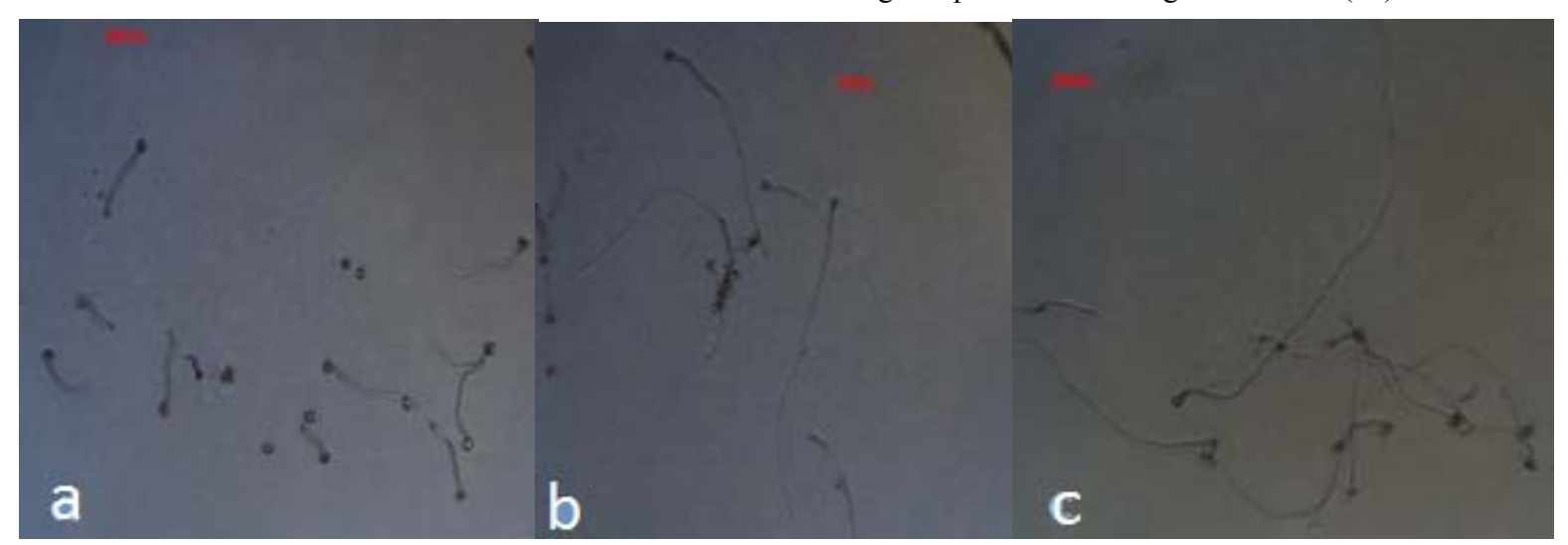

Fig. 2 The growth of the pollen tubes in a liquid medium added fructose (a), glucose (b) and sucrose (c). 


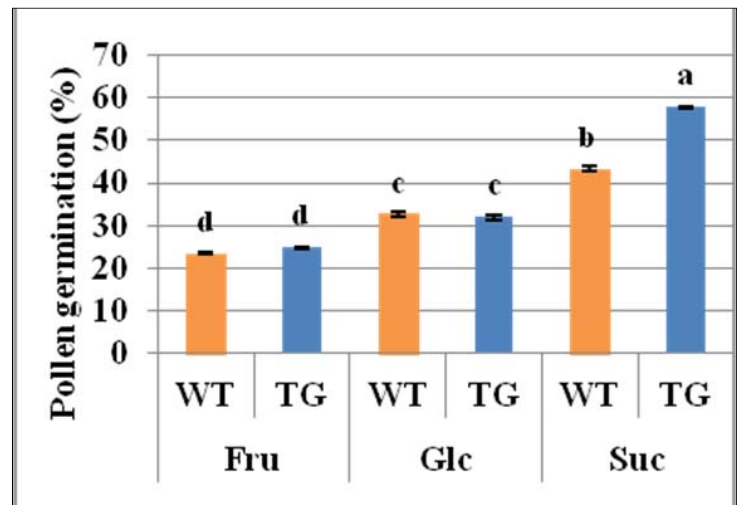

Fig. 3 Pollen germinations of wild-type (WT) and transgenic (TG) tomato plants incubated in medium containing fructose (Fru), glucose (GIc) or sucrose (Suc).

Data represent mean $\pm \mathrm{SE}$; different letters indicate significant differences in ANOVA with $\alpha=0.05$.

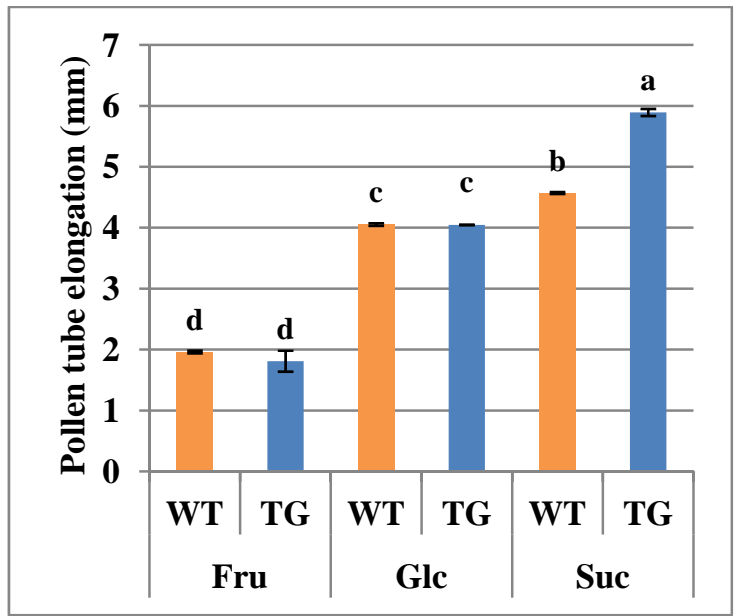

Fig. 4 Pollen tube elongation of wild-type (WT) and transgenic (TG) tomato plants incubated in media containing fructose (Fru), glucose (Glc) or sucrose (Suc).

Data represent mean $\pm \mathrm{SE}$; different letters indicate significant differences in ANOVA with $\alpha=0.05$.

Similar to pollen germination, the pollen tube elongation of the transgenic plant was longer than those from the wild-type plants. This phenomenon also occurred in medium containing sucrose only, but it did not occur in glucose and fructose media (Fig. 4).

From those experiments mentioned above, sucrose plays an important role in the regulation of pollen germination and the pollen tube elongation. Sucrose may play a role in these processes to provide a carbon source for growth and development, in which the sucrose consists of glucose and fructose. These experiments also prove that cell wall invertase affected the pollen germination and pollen tube elongation, in which the pollen grains originated from the transgenic plants germinated and elongated longer than those from wild-type plants. These occur on sucrose medium only. As such, it suggests that cell wall invertase regulates the pollen germination and pollen tube elongation through sucrose hydrolysis. This result support the proposed model that sucrose transported into pollen tube is hydrolyzed by invertase enzyme into glucose and fructose in cell wall [20]. This result is also consistent with the previous reports that sucrose stimulated pollen germination [24-28]. Interestingly, this result suggests that sucrose enhanced these processes through sucrose hydrolysis to glucose and fructose by the activity of invertase enzyme. According to several previous studies, glucose and fructose from sucrose hydrolysis by the cell wall invertase play a very important role in cell metabolism, signal molecules and regulators in the regulation of gene expression [14, 29-36]. Furthermore, the resultant sugars of sucrose hydrolysis must be transported to the cytoplasm by a monosaccharide transporter [37-40].

Additionally, it was demonstrated that pollen germination and pollen tube elongation were regulated by sucrose hydrolyzed by cell wall invertase, but not by differences in the added sugar concentrations. This reason is based on a concept that sucrose consists of glucose and fructose, which makes it have two times larger of osmotic pressure. To verify the hypothesis, a similar study was conducted by changing the different sugar concentrations with $29 \mathrm{mM}$ sucrose, $58 \mathrm{mM}$ glucose and $58 \mathrm{mM}$ fructose. Apparently, the results obtained were similar to those of previous experiments, namely, the pollen germination and pollen tubes elongation from transgenic plants occurred greater than those from wild-type plants in a medium containing sucrose (Fig. 5).

The results of the experiment ascertain that the 


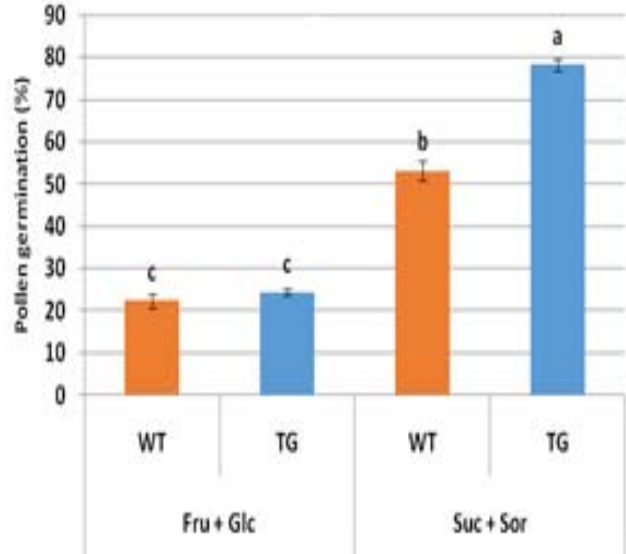

(a) Percentage of pollen germination

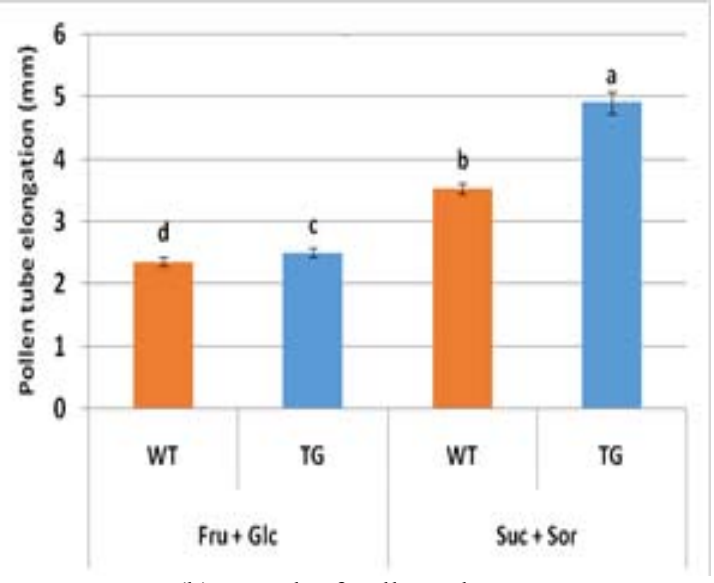

(b) Length of pollen tube

Fig. 5 Percentage of pollen germination (a) and length of pollen tube (b) in media added with a mixture of fructose and glucose and a mixture of sucrose and sorbitol.

Data represent mean $\pm \mathrm{SE}$; different letters indicate significant differences in ANOVA with $\alpha=0.05$.

role of sucrose could not be replaced by a mixture of glucose and fructose. As shown in Fig. 5 that the pollen germination and pollen tube elongation remain higher in sucrose (+ sorbitol) than in the glucose and fructose media. It means that the sucrose is highly required in the process of the germination and elongation of the pollen. Note that sorbitol added with sucrose acts as an osmotic balance only, because it could not be metabolized. The results of the study support several views that sugars generated from photosynthesis and transported to sink cells including pollen and pollen tube were in a sucrose form [13-15, $20,25]$. It is also proposed that apoplasmictransported sucrose will be decomposed by invertase into glucose and fructose, and the monosaccharide may be transported into the cytoplasm by monosaccharide transporter [20].

\section{Conclusions}

From this study, it can be concluded that sucrose enhances germination of pollen and elongation of the pollen tube through a sucrose hydrolysis by cell wall invertase mechanism. It is recommended to investigate a regulation of pollen germination and pollen tube elongation in pistilous tissues (in vivo) by the cell wall invertase.

\section{References}

[1] Krichevsky, A., Kozlovsky, S. V., Tian, G. W., Chen, M. H., Zaltsman, A., and Citovsky, V. 2007. "How Pollen Tubes Grow.” Developmental Biology 303 (2): 405-20.

[2] Johnston, A. J., Meier, P., Gheyselinck, J., Wuest, S. E., Federer, M., Schlagenhauf, E., Becker, J. D., and Grossniklaus, U. 2007. "Genetic Subtraction Profiling Identifies Genes Essential for Arabidopsis Reproduction and Reveals Interaction between the Female Gametophyte and the Maternal Sporophyte." Genome Biol. 8 (10): R204.

[3] Li, M. N., Xu, W. Y., Yang, W. Q., Kong, Z. S., and Xue, Y. B. 2007. "Genome-Wide Gene Expression Profiling Reveals Conserved and Novel Molecular Functions of the Stigma in Rice." Plant Physiol. 144 (4): 1797-812.

[4] Chae, K., and Lord, E. M. 2011. "Pollen Tube Growth and Guidance: Roles of Small, Secreted Proteins." Annals of Botany 108 (4): 627-36.

[5] Zou, Y., Aggarwal, M., Zheng, W. G., Wu, H. M., and Cheung, A. Y. 2011. "Receptor-Like Kinases as Surface Regulators for RAC/ROP-Mediated Pollen Tube Growth and Interaction with the Pistil." AoB Plants 11 (1): 1-14.

[6] Pertl-Obermeyer, H., Schulze, W. X., and Obermeyer, G. 2014. "In Vivo Cross-Linking Combined with Mass Spectrometry Analysis Reveals Receptor-Like Kinases and $\mathrm{Ca}^{2+}$ Signalling Proteins as Putative Interaction Partners of Pollen Plasma Membrane $\mathrm{H}^{+}$ATPases." J. Proteomics 108: 17-29.

[7] Cheung, A. Y., Boavida, L. C., Aggarwal, M., Wu, H. M., and Feijó, J. A. 2010. "The Pollen Tube Journey in the Pistil and Imaging the in Vivo Process by Two-Photon Microscopy." Journal of Experimental Botany 61 (7): 


\section{Pollen Germination and Pollen Tube Elongation of Tomato (Lycopersicum esculentum L.) Regulated by Cell Wall Invertase through Sucrose Hydrolysis}

1907-15.

[8] Cabello, J. V., Lodeyro, A. F., and Zurbriggen, M. D. 2014. "Novel Perspectives for the Engineering of Abiotic Stress Tolerance in Plants." Curr. Opin. Biotechnol. 26: $62-70$.

[9] Ruan, Y. L., Jin, Y., Yang, Y. J., Li, G. J., and Boyer, J. S. 2010. "Sugar Input, Metabolism, and Signaling Mediated by Invertase: Roles in Development, Yield Potential, and Response to Drought and Heat." Molecular Plant 3 (6): 942-55.

[10] Dresselhaus, T., and Franklin-Tong, N. 2013. "Male-Female Crosstalk during Pollen Germination, Tube Growth and Guidance, and Double Fertilization." Mol. Plant 6 (4): 1018-36.

[11] Abdelgadir, H. A., Johnson, S. D., and Van Staden, J. 2012. "Pollen Viability, Pollen Germination and Pollen Tube Growth in the Biofuel Seed Crop Jatropha curcas (Euphorbiaceae)." South African J. Bot. 79: 132-9.

[12] Márton, M. L., and Dresselhaus, T. 2010. "Female Gametophyte-Controlled Pollen Tube Guidance." Biochem. Soc. Trans. 38 (2): 627-30.

[13] Ponnu, J., Wahl, V., and Schmid, M. 2011. "Trehalose-6-Phosphate: Connecting Plant Metabolism and Development." Front. Plant Sci. 2: 70.

[14] Wind, J., Smeekens, S., and Hanson, J. 2010. "Sucrose: Metabolite and Signaling Molecule." Phytochemistry 71 (14-15): 1610-4.

[15] Winter, H., and Huber, S. C. 2000. "Regulation of Sucrose Metabolism in Higher Plants: Localization and Regulation of Activity of Key Enzymes." Crit. Rev. Biochem. Mol. Biol. 35 (4): 253-89.

[16] Jin, Y., Ni, D. A., and Ruan, Y. L. 2009. "Posttranslational Elevation of Cell Wall Invertase Activity by Silencing Its Inhibitor in Tomato Delays Leaf Senescence and Increases Seed Weight and Fruit Hexose Level." Plant Cell 21 (7): 2072-89.

[17] Palmer, W. M., Ru, L., Jin, Y., Patrick, J. W., and Ruan, Y. L. 2015. "Tomato Ovary-to-Fruit Transition Is Characterized by a Spatial Shift of mRNAs for Cell Wall Invertase and Its Inhibitor with the Encoded Proteins Localized to Sieve Elements." Mol. Plant 8 (2): 315-28.

[18] Ruan, Y. L. 2014. "Sucrose Metabolism: Gateway to Diverse Carbon Use and Sugar Signaling." Annu. Rev. Plant Biol. 65: 33-67.

[19] Wang, L., Li, X. R., Lian, H., Ni, D. A., He, Y. K., Chen, X. Y., and Ruan, Y. L. 2010. "Evidence that High Activity of Vacuolar Invertase Is Required for Cotton Fiber and Arabidopsis Root Elongation through Osmotic Dependent and Independent Pathways, Respectively." Plant Physiol. 154 (2): 744-56.

[20] Ylstra, B., Garrido, D., Busscher, J., and Van Tunen, A. J.
1998. "Hexose Transport in Growing Petunia Pollen Tubes and Characterization of a Pollen-Specific, Putative Monosaccharide Transporter." Plant Physiol. 118 (1): 297-304.

[21] Zanor, M. I., Osorio, S., Nunes-Nesi, A., Carrari, F., Lohse, M., Usadel, B., Kühn, C., Bleiss, W., Giavalisco, P., Willmitzer, L., Sulpice, R., Zhou, Y. H., and Fernie, A R. 2009. "RNA Interference of LIN5 in Tomato Confirms Its Role in Controlling Brix Content, Uncovers the Influence of Sugars on the Levels of Fruit Hormones, and Demonstrates the Importance of Sucrose Cleavage for Normal Fruit Development and Fertility." Plant Physiol. 150 (3): 1204-18.

[22] Goetz, M., Godt, D. E., Guivarc'h, A., Kahmann, U., Chriqui, D., and Roitsch, T. 2001. "Induction of Male Sterility in Plants by Metabolic Engineering of the Carbohydrate Supply." Proc. Natl. Acad. Sci. USA 98, (11): 6522-7.

[23] Kakani, V. G., Reddy, K. R., Koti, S., Wallace, T. P., Prasad, P. V. V., Reddy, V. R., and Zhao, D. 2005. "Differences in in Vitro Pollen Germination and Pollen Tube Growth of Cotton Cultivars in Response to High Temperature." Ann. Bot. 96 (1): 59-67.

[24] Okusaka, K., and Hiratsuka, S. 2009. "Fructose Inhibits Pear Pollen Germination on Agar Medium without Loss of Viability." Scientia Horticulturae (Amsterdam) 122 (1) 51-5.

[25] Hackel, A., Schauer, N., Carrari, F., Fernie, A. R., Grimm, B., and Kühn, C. 2006. "Sucrose Transporter LeSUT1 and LeSUT2 Inhibition Affects Tomato Fruit Development in Different Ways." Plant J. 45 (2): 180-92.

[26] Sharafi, Y., and Bahmani, A. 2011. "In Vitro Study of Pollen Traits after Short Storage in Some Almond, Apricot and Sweet Cherry Favorable Genotypes." J. Med. Plants Res. 5 (2): 266-9.

[27] Reger, B. J., Pressey, R., and Chaubal, R. 1992. "In Vitro Chemotropism of Pearl Millet Pollen Tubes to Stigma Tissue: A Response to Glucose Produced in the Medium by Tissue-Bound Invertase." Sex. Plant Reprod. 5 (3): 201-5.

[28] Wang, Z. Y., Ge, Y., Scott, M., and Spangenberg, G. 2004. "Viability and Longevity of Pollen from Transgenic and Nontransgenic Tall Fescue Plants (Festuca arundinacea) (Poaceae) Plants.” Am. J. Bot. 91 (4): 523-30.

[29] Jain, M., Chourey, P. S., Li, Q. B., and Pring, D. R. 2008. "Expression of Cell Wall Invertase and Several Other Genes of Sugar Metabolism in Relation to Seed Development in Sorghum (Sorghum bicolor)." J. Plant Physiol. 165 (3): 331-44.

[30] Oliver, S. N., Dennis, E. S., and Dolferus, R. 2007. “ABA Regulates Apoplastic Sugar Transport and Is a Potential 


\section{Regulated by Cell Wall Invertase through Sucrose Hydrolysis}

Signal for Cold-Induced Pollen Sterility in Rice.” Plant Cell Physiol. 48 (9): 1319-30.

[31] Riou-khamlichi, C., Menges, M., Murray, J. A. H., and Sandra-Healy, J. M. 2000. "Sugar Control of the Plant Cell Cycle: Differential Regulation of Arabidopsis D-Type Cyclin Gene Expression.” Mol. Cell. Biol. 20 (13): 4513-21.

[32] Tuteja, N., and Sopory, S. K. 2008. "Chemical Signaling under Abiotic Stress Environment in Plants." Plant Signal. Behav. 3 (8): 525-36.

[33] Pressman, E., Shaked, R., Shen, S., Altahan, L., and Firon, N. 2012. "Variations in Carbohydrate Content and Sucrose-Metabolizing Enzymes in Tomato." Am. J. Plant Sci. 3 (2): 252-60.

[34] Von Schweinichen, C., and Büttner, M. 2005. "Expression of a Plant Cell Wall Invertase in Roots of Arabidopsis Leads to Early Flowering and an Increase in Whole Plant Biomass." Plant Biol. 7 (5): 469-75.

[35] Reca, I. B., Brutus, A., D'Avino, R., Villard, C., Bellincampi, D., and Giardina, T. 2008. "Molecular Cloning, Expression and Characterization of a Novel Apoplastic Invertase Inhibitor from Tomato (Solanum lycopersicum) and Its Use to Purify a Vacuolar Invertase."

\author{
Biochimie 90 (11-12): 1611-23.
}

[36] Ahmed, H. E., Youssef, E. A., Kord, M. A., and Qaid, E. A. 2013. "Trehalose Accumulation in Wheat Plant Promotes Sucrose and Starch Biosynthesis." Jordan J. Biol. Sci. 6 (2): 143-50.

[37] Schneidereit, A., Scholz-Starke, J., and Büttner, M. 2003. "Functional Characterization and Expression Analyses of the Glucose-Specific AtSTP9 Monosaccharide Transporter in Pollen of Arabidopsis." Plant Physiol. 133 (1): 182-90.

[38] Butner, M. 2007. "The Monosaccharide Transporter(-Like) Gene Family in Arabidopsis." FEBS Letters 581 (12): 2318-24.

[39] Dibley, S. J., Gear, M. L., Yang, X., Rosche, E. G., Offler, C. E., Mccurdy, D. W., and Patrick, J. W. 2005. "Temporal and Spatial Expression of Hexose Transporters in Developing Tomato (Lycopersicon esculentum) Fruit." Funct. Plant Biol. 32 (9): 777-85.

[40] Sivitz, A. B., Reinders, A., and Ward, J. M. 2008. "Arabidopsis Sucrose Transporter AtSUC1 Is Important for Pollen Germination and Sucrose-Induced Anthocyanin Accumulation." Plant Physiol. 147 (1): 92-100. 